\title{
Effects of Online Courses in STEM on Institutional Integration
}

\author{
Lawrence O. Flowers, Ph.D. \\ Assistant Professor of Microbiology \\ Department of Biological Sciences, Fayetteville State University \\ E-mail: lflowers@uncfsu.edu \\ James E. Raynor, Jr., Ph.D. \\ Associate Professor of Cellular and Molecular Biology \\ Department of Biological Sciences, Fayetteville State University \\ E-mail: jraynor@uncfsu.edu \\ Erin N. White, Ph.D. \\ Associate Professor of Biology \\ Department of Biological Sciences, Fayetteville State University \\ E-mail: ewhite@uncfsu.edu
}

Received: March 22, 2013

doi:10.5296/jse.v3i2.3422
Accepted: April 8, $2013 \quad$ Published: May 1, 2013

URL: http://dx.doi.org/10.5296/jse.v3i2.3422

\begin{abstract}
Improving the instructional curriculum is a top priority for online instructors. Stakeholders of online science education initiatives firmly agree that additional research is needed to address many issues facing the proliferation of online science courses in the United States. To that end, aggressive steps must be continually taken to develop quality educational methods designed to promote both academic and social growth. Previous research has demonstrated that students who report a higher degree of university involvement and peer interaction also report a higher level of satisfaction with the academic experience. The current study analyzed the perceptions of academic and social integration of undergraduates enrolled in online and traditional science, technology, engineering, and mathematics (STEM) courses using the
\end{abstract}




\section{Macrothink}

Institutional Integration Scale (IIS). The Institutional Integration Scale was devised to measure peer-group interaction and student-faculty interaction during a college semester and is based on the seminal work by Tinto that focused on student persistence and commitment to degree attainment. The IIS consists of five subscales: peer-group interactions, interactions with faculty, institutional and goal commitments, academic and intellectual development, and faculty concern for student development and teaching. Both the Peer-group Interactions Subscale and Interactions with faculty Subscales demonstrated significant, yet direct negative effects suggesting that online students perceived reduced interaction between fellow classmates and the instructor during their online course. Future research and teaching strategies designed to promote student interaction in the online environment are recommended in the article.

Keywords: Institutional integration, Online learning, Distance education, STEM, Pedagogical strategies 


\section{Introduction}

While online education programs and degrees continue to flourish across the country, student persistence in online courses still remains an elusive issue. Improving course persistence and student graduation rates remains a top priority among online faculty and university administrators. The educational research literature contains many studies on diagnosing retention factors, identifying at-risk students for low academic performance, and developing strategies to combat college student withdrawal at all levels (Lascher \& Offenstein, 2013; Milem \& Berger, 1997; Rohr, 2013; Tinto, 1993). The Institutional Integration Scale (IIS) was developed by Pascarella and Terenzini (1980) and derived from Tinto's (1975) work on college student attrition factors. The IIS assesses five different aspects of academic and social integration such as peer interactions, faculty interactions, perceived faculty concern for their academic development, personal academic and intellectual development, and their personal commitment to scholarly goals. The IIS provide students with an opportunity to report on their perceived academic and social integration. Academic and social integration are extremely important factors as it relates to early withdrawal from college. The ability of college students to successfully interact with other students and faculty and to utilize those experiences to develop quality academic and intellectual skills is a guiding factor in improving graduation rates.

Moreover, the capacity of students to utilize institutional student support services to improve academic outcomes also plays a major role in college student success. The guiding principle regarding student persistence is that students who have greater involvement and integration with academic and social features of the university are less likely to withdraw from courses and the university. The increased support from both faculty and student affairs professionals provide students insight to university life and academic tools and resources that build confidence for improved course work performance (Blake, 2007). For example, knowledge about career services and tutorial services on campus can promote better quality study skills that result in higher educational attainment. The above factors also enhance student commitment to course completion and graduation. The current investigation underscores the importance of assessing noncognitive factors such as institutional integration to design methods to improve academic outcomes. The purpose of the current research study was to address the following research question: Controlling for differences in precollege characteristics, institutional characteristics, academic experiences, and nonacademic experiences, to what extent does the learning environment (online vs. traditional) influence academic and social integration for students in STEM courses?

\section{Methodology}

\section{Participants}

The Institutional Integration Scale was administered to both STEM majors and non-STEM majors either enrolled in a traditional (e.g., face-to-face) STEM course or an online STEM course. The study consisted of freshman, sophomores, juniors, and seniors at a small university in the southeastern United States. Both male (38.6\%) and female (61.4\%) undergraduate students participated in the research study. No graduate students participated in 
the current study. Completed surveys were used in the analysis of the data. Over $77 \%$ of the participating students reported to being enrolled in at least one online course during the time of the study.

\section{Procedure}

Data collection for the quantitative research study consisted of a Demographic Questionnaire and the Institutional Integration Scale, which was completed at the end of the academic semester.

The Demographic Questionnaire consisted of items designed to ascertain information about participants along four dimensions: precollege and demographic characteristics (e.g., gender, socioeconomic status, high school grade point average, undergraduate grade point average, age, etc.), institutional characteristics (e.g., institutional selectivity, perceptions of the campus climate, etc.), academic experiences in college (e.g., college major, hours per week spent studying, etc.), and nonacademic experiences in college (e.g., college residence, Greek affiliation, hours per week spent working on- or off-campus, participation in intercollegiate athletics, etc.). Data collected from electronic surveys from online and traditional students were transferred into Predictive Analysis Software (PASW), cleaned, and coded for functionality. More specifically, items from each instrument were analyzed to ensure their suitability for statistical analysis (e.g., recoded missing values, computed subscale scores, produced psychometric properties, etc.). The independent variable consisted of course enrollment.

A categorical variable was coded: $1=$ enrolled in an online STEM course; $0=$ enrolled in a traditional STEM course. The dependent variable measured aspects of institutional integration. Control variables included age, gender, grade point average, year in school, residence status, hours spent studying per week, and hours worked on- and off-campus. The instrumentation used in the study enabled the researchers to better understand the effects of learning environments on student outcomes while controlling for the effects of student demographic characteristics and academic experiences. It should be pointed out that the online student participants were required to create an introduction thread and participate in a weekly online discussion board. Specifically, students were instructed to respond to general discussion board topics and to respond to other classmates' posts. Each online STEM course also contained an asynchronous environment that allowed students the opportunity to interact with each other. In the beginning of the course students were asked to write a brief statement in which they discussed their career goals, reasons for enrolling, classification, and interesting personal information.

\section{Institutional Integration Scale}

The Institutional Integration Scale (IIS) consists of a 30-item, Likert-type scale (1 = strongly disagree to 5 = strongly agree). It measures the extent to which students have interactions on campus that promote retention and academic and social development in college (Pascarella, 1980; Pascarella \& Terenzini, 1980). The IIS has five subscales: peer-group interactions subscale (7 items), interactions with faculty subscale (5 items), faculty concern for student 


\section{Macrothink Institute $^{\mathrm{TM}}$}

development and teaching subscale (5 items), academic and intellectual development subscale (7 items), and institutional and goal commitments subscale (6 items). Data from the undergraduate student participants were used to calculate the regression coefficients. Construct validity evidence supports the utility of this instrument (French \& Oakes, 2004; Pascarella, 1985).

\section{Results}

Statistically controlling for differences in precollege characteristics, institutional characteristics, academic experiences, and nonacademic experiences, students in traditional STEM courses were more likely to perceive and engage in academic and social integration experiences compared to students who took online STEM courses. Table 1 summarizes the direct effects of taking an online STEM course (versus a traditional STEM course) on students' academic and social integration. Multiple regression analyses demonstrated that taking an online STEM course had significant and negative direct effects on students' scores on the Peer-Group Interactions Subscale $(B=-1.142, p<.05)$ and the Interactions with Faculty Subscale $(\mathrm{B}=-1.053, \mathrm{p}<.05)$. While not statistically significant, the effects of taking an online STEM course yield mostly negative coefficients on the Academic and Intellectual Development Subscale (B = -.570) and Institutional and Goal Commitments Subscale $(\mathrm{B}=$ -.572). The Faculty Concern for Student Development and Teaching Subscale $(\mathrm{B}=.236)$ did not yield statistically significant evidence, but yield a positive coefficient.

Table 1. Effects of Online STEM Courses on Academic and Social Integration ${ }^{\mathrm{a}, \mathrm{b}}$

\begin{tabular}{|c|c|}
\hline Institutional Integration Scale & Regression Coefficient \\
\hline Peer-Group Interactions Subscale & $\begin{array}{c}-1.142^{* *} \\
(-.125)\end{array}$ \\
\hline Interactions with Faculty Subscale & $\begin{array}{c}-1.053^{* *} \\
(-.125)\end{array}$ \\
\hline Institutional and Goal Commitments Subscale & $\begin{array}{c}-.572 \\
(-.062)\end{array}$ \\
\hline Academic and Intellectual Development Subscale & $\begin{array}{c}-.570 \\
(-.066)\end{array}$ \\
\hline Faculty Concern for Student Development and Teaching Subscale & $\begin{array}{c}.236 \\
(.039)\end{array}$ \\
\hline \multicolumn{2}{|c|}{$\begin{array}{l}\text { a Top number is the unstandardized regression coefficient, number in parentheses is the standardized regression } \\
\text { coefficient. } \\
\text { bStatistically controlling for age, gender, year in school, grade point average, residence status, hours spent } \\
\text { studying per week, and hours spent working on-campus and off-campus per week. } \\
{ }^{* * *} \mathrm{p}<.01 * * \mathrm{p}<.05 * \mathrm{p}<.10\end{array}$} \\
\hline
\end{tabular}




\section{Discussion}

In addition to the fundamental work proffered by Tinto (1975), Astin also provided insights into the importance of the role of educators in creating an academic environment that promotes student engagement and interaction that leads to more successful academic and social outcomes for college students (Astin, 1984). Facilitating interaction between students and between students and faculty is an important aim for online instructors and may address the trepidation over online student persistence (Boston, Ice, \& Gibson, 2011). Significant research supports the academic benefits associated with increased motivation and increased learning gains in online courses due to enhanced interaction and increased social presence among online instructors (Anderson, 2006; Wei, Chen, \& Kinshuk, 2012). Recently, York and Richardson (2012) explicated the factors that can be utilized or modified by online STEM faculty to raise the level of social interaction.

Those factors include: group work, course environment, model use, discussion question type and assessment, feedback type, discourse guidelines, and instructor participation. The Institutional Integration Scale (IIS) is a functional instrument designed to evaluate a college students' degree of interaction with faculty, other students, and the university atmosphere. Data from this study provides potentially useful information about pedagogical strategies that can be employed in both online and traditional STEM courses. Typically, the Peer-Group Interactions Subscale and Interactions with Faculty Subscale are utilized to explore the social assimilation inside the classroom and outside the classroom. The other three subscales (e.g., Institutional and Goal Commitments Subscale, Academic and Intellectual Development Subscale, and Faculty Concern for Student Development and Teaching Subscale) are primarily used to explore academic factors that affect student success. Based on the significant results generated in the Peer-Group Interactions Subscale and Interactions with Faculty Subscale the focus of this research article is centered on strategies to reduce the negative effects observed on these two subscales.

The negative coefficients obtained in the study indicate a negative relationship between the independent variable (course enrollment) and the dependent variable (institutional integration) (Lewis-Beck, 1995). Based on the coding system used in the analysis an increase in online STEM course enrollment resulted in a statistically significant decrease on the Peer-Group Interactions Subscale $(-1.142, \mathrm{p}<.05)$ and Interactions with Faculty Subscale $(-1.053, \mathrm{p}$ $<.05$ ), suggesting that online students have negative perceptions of peer-group interaction and faculty interaction compared to traditional students who have a more favorable perception of peer-group interaction and faculty interaction.

\section{Pedagogical Implications and Future Research}

The negative effects observed for the Peer-Group Interactions Subscale and Interactions with Faculty Subscale are not completely surprising. One of the major complaints from online students is the reduced interaction with other students and faculty in online courses. Dennen, Darabi, and Smith (2007) noted that increasing interpersonal interaction among faculty and students during the semester can have positive outcomes on influencing college student attitudes and enhance academic performance. To improve Peer-Group Interactions Subscale 
scores, online professors could design group projects that are aligned with course objectives. Group projects would enhance peer interactions through cooperative intellectual sharing. The inclusion of video-based online individual assignments coupled with a synchronous question and answer period could also enhance student interaction in an online course. Further, while discussion boards were used in the STEM online courses in this study, Nandi, Hamilton, and Harland (2012) note specific strategies for improving discussion board assignments to enhance student interaction and faculty-student interaction such as careful monitoring and feedback by the online instructor. Online faculty should consider other forms of feedback that complement the standard written feedback when evaluating online discussion board assignments. Studies by Ice et al. (2007) and Oomen-Early et al. (2008) revealed that audio feedback is a substantial improvement to written feedback alone and that a combination of written feedback and audio feedback leads to increase faculty-student interaction and higher levels of student satisfaction in the online course. Moreover, the construction of detailed rubrics to specify student interaction during the semester would also improve communication between students in the online environment by providing clear guidelines regarding interaction policies during the semester and may significantly improve scores on the Peer-Group Interactions Subscale and Interactions with Faculty Subscale.

Continued investigations into procedures to improve online learning must be directed at exploring not only strictly academic (e.g., cognitive) factors, but also social (e.g., noncognitive) factors. Moreover, to improve online learning in STEM disciplines quantitative and qualitative research must be designed to collect data regarding students' academic orientations, educational outcomes, and academic experiences in online and traditional STEM courses. To obtain more

in-depth data, qualitative studies employing individual student interviews and student focus groups must examine similarities and differences in the academic experiences and educational outcomes of undergraduate students enrolled in online distance education courses in the STEM majors from a variety of different institutional types (e.g., public, private). Grounded theory-based analytical approaches would yield substantive data regarding the intricate nature of online learning in STEM fields (Strauss \& Corbin, 1990). The validity and reliability of qualitative studies can be enhanced by providing opportunities for students to adequately respond to open-ended interview questions over an extended period of time and by recording each interview to ensure data transcription accuracy, as well as giving participants an opportunity to review and revise their responses to the interview protocol (Mason, 2002).

A major limitation of the current study is that data was only collected at the end of the semester. Thus, while data in the study reflected significant direct negative effects on the Peer Interactions Subscale and Interactions with Faculty Subscale, researchers are unable to determine whether the instructional strategies employed during the semester were effective at improving student interaction. Future studies will include both a pre-test and a post-test to evaluate the efficacy of implementing novel student interaction instructional methods in online STEM courses. 
At its core, science is a collaborative endeavor; therefore, the inclusion of educational methods to increase interaction among students may help students develop team-building skills and collaboration skills which are typically focal points of STEM departments' objectives.

The limited sample size precludes the generalizability of the findings, but does offer an excellent springboard for future studies in this area where a larger sample size is employed. The constant reassessment of college student persistence factors in both online and traditional STEM courses will permit faculty to adjust learning objectives and strategies to fit the needs of students which may directly correlate with a greater level of student satisfaction and commitment to course completion and graduation.

\section{References}

Anderson, T. (2006). Interaction in learning and teaching on the educational semantic web. In: Juwah, C. (Ed.), Interactions in online education, 141-155, New York, NY: Routledge.

Astin, A. W. (1984). Student involvement: A developmental theory for higher education. Journal of College Student Personnel, 25(4), 297-308.

Blake, J. (2007). The crucial role of student affairs professionals in the learning process. New Directions for Student Services, 117, 65-72. http://dx.doi.org/10.1002/ss.234

Boston, W., Ice, P., \& Gibson, A. (2011). Comprehensive assessment of student retention in online learning environments. Online Journal of Distance Learning Administration, 14(1).

Dennen, V., Darabi, A., \& Smith, L. (2007). Instructor-learner interaction in online courses: The relative perceived importance of particular instructor actions on performance and satisfaction. $\quad$ Distance $\quad$ Education, $\quad 28(1), \quad 65-79$. http://dx.doi.org/10.1080/01587910701305319

French, B., \& Oakes, W. (2004). Reliability and validity evidence for the institutional integration scale. Educational and Psychological Measurement, 64, 88-98. http://dx.doi.org/10.1177/0013164403258458

Ice, P., Curtis, R., Phillips, P., \& Wells, J. (2007). Using asynchronous audio feedback to enhance teaching presence and students' sense of community. Journal of Asynchronous Learning Networks, 11, 3-25.

Lascher, E., \& Offenstein, J. (2013). Campus racial climate and student academic outcomes: A critique of prior research and recommendations for future study. Journal of College Student Retention: Research, Theory \& Practice, 14(2), 265-277.

Lewis-Beck, M. S. (1995). Data Analysis: An Introduction. Thousand Oaks, CA: SAGE Publications.

Mason, J. (2002). Qualitative researching (2nd ed.). Newbury, CA: Sage.

Milem, J. F., \& Berger, J. B. (1997). A modified model of college student persistence: Exploring the relationship between Astin's theory of involvement and Tinto's theory of 
student departure. Journal of College Student Development, 38(4), 387-400.

Nandi, D., Hamilton, M., \& Harland, J. (2012). Evaluating the quality of interaction in asynchronous discussion forums in fully online courses. Distance Education, 33(1), 5-30. http://dx.doi.org/10.1080/01587919.2012.667957

Oomen-Early, J., Bold, M., Wiginton, K. L., Gallien, T. L., \& Anderson, N. (2008). Using asynchronous audio communication (AAC) in the online classroom: A comparative study. Journal of Online Learning and Teaching, 4(3), 267-276.

Pascarella, E. T. (1980). Student-faculty informal contact and college outcomes. Review of Educational Research, 50(4), 545-595.

Pascarella, E. T. (1985). College environmental influences on learning and cognitive development: A critical review and synthesis. In J. C. Smart (Ed.), Higher education: Handbook of theory and research, 1, 1-61. New York, NY: Agathon Press.

Pascarella, E. T., \& Terenzini, P. T. (1980). Predicting freshman persistence and voluntary dropout decisions from a theoretical model. Journal of Higher Education, 51(1), 60-75. http://dx.doi.org/10.2307/1981125

Rohr, S. (2013). How well does the SAT and GPA predict the retention of science, technology, engineering, mathematics, and business students. Journal of College Student Retention: Research, Theory \& Practice, 14(2), 195-208.

Strauss, A., \& Corbin, J. (1990). Basics of qualitative research: Grounded theory procedures and techniques (2nd ed.). Newbury Park, CA: Sage.

Tinto, V. (1975). Dropout from higher education: A theoretical synthesis of recent research. Review of Educational Research, 45(1), 89-125.

Tinto, V. (1993). Leaving college: Rethinking the causes and cures of student attrition (2nd ed.). Chicago, IL: University of Chicago Press.

Wei, C., Chen, N., \& Kinshuk. (2012). A model for social presence in online classrooms. Educational Technology Research and Development, 60(3), 529-545. http://dx.doi.org/10.1007/s11423-012-9234-9

York, C., \& Richardson, J. (2012). Interpersonal interaction in online learning: Experienced online instructors' perceptions of influencing factors. Journal of Asynchronous Learning Networks, 16(4), 83-98.

\section{Acknowledgements}

This work was supported by a grant funded by the National Science Foundation (HRD-0811728). 